\title{
A 34-year-old man with urethral discharge
}

\author{
Gabriel W. Rebick MD, Vanessa G. Allen MD, Wayne L. Gold MD
}

Competing interests: None declared.

This article has been peer reviewed.

Correspondence to: Gabriel W. Rebick,

Gabriel.rebick

@mail.utoronto.ca

CMAJ 2013. DOI:10.1503 /cmaj.121776

\begin{abstract}
A 34-year-old man who has sex with men and has a remote history of primary syphilis presents to his primary care physician with painful urination and a purulent urethral discharge. He received unprotected oral sex from a new sexual partner 3 weeks ago. Two weeks before his current visit, he presented to a walk-in clinic and had nucleic acid amplification testing of the urethral discharge, the results of which were positive for Neisseria gonorrhoeae. The patient received a single oral dose of ciprofloxacin $500 \mathrm{mg}$ with no improvement of symptoms.
\end{abstract}

\section{What is the most likely cause of this patient's urethritis?}

Chlamydia trachomatis and $N$. gonorrhoeae are the most common causes of urethritis in men. Other causes include Mycoplasma genitalium, Trichomonas vaginalis, Ureaplasma urealyticum and herpes simplex virus. ${ }^{1}$ Between 1997 and 2009, rates of gonococcal infections in Canada more than doubled to 33.1 cases per 100000 popula-

Table 1: Testing and treatment for uncomplicated gonococcal infection ${ }^{1,3}$

\begin{tabular}{|c|c|c|}
\hline Specimen site & Test & Preferred treatment* ${ }^{*}$ \\
\hline Urine & NAAT & \multirow{4}{*}{$\begin{array}{c}\text { Ceftriaxoneף } 250 \mathrm{mg} \\
\text { intramuscularly once or } \\
\text { cefixime } 800 \mathrm{mg} \text { orally once } \\
\text { plus } \\
\text { azithromycin } 1 \mathrm{~g} \text { orally once }\end{array}$} \\
\hline Male urethra & $\begin{array}{l}\text { Gram stain, culture } \\
\text { or NAAT‡ }\end{array}$ & \\
\hline $\begin{array}{l}\text { Female urethra or } \\
\text { endocervix }\end{array}$ & $\begin{array}{l}\text { Gram stain, culture } \\
\text { or NAAT‡ }\end{array}$ & \\
\hline Rectum & Culture or NAAT§ & \\
\hline Pharynx & Culture or NAAT§ & $\begin{array}{c}\text { Ceftriaxone } 250 \mathrm{mg} \\
\text { intramuscularly once } \\
\text { plus } \\
\text { azithromycin } 1 \mathrm{~g} \text { orally once }\end{array}$ \\
\hline
\end{tabular}

Note: NAAT $=$ nucleic acid amplification test.

*Alternative treatments include azithromycin $2 \mathrm{~g}$ orally once, spectinomycin $2 \mathrm{~g}$

intramuscularly once, ciprofloxacin $500 \mathrm{mg}$ orally once and ofloxacin $400 \mathrm{mg}$ orally once.

Fluoroquinolones should be used only for culture-proven susceptible infections, or if local resistance is less than $5 \%$ and a test of cure can be performed.

tIn all symptomatic men who have sex with men, culture should be performed before treatment to obtain drug susceptibilities. ${ }^{3}$

\#In asymptomatic individuals, NAAT is the preferred screening test (urine for men and endocervical swab for women). For women, urine may be used if endocervical swab is unavailable.'

SNAAT may be performed for rectal and pharyngeal cultures in microbiology laboratories that have validated tests for these body sites.

IIIn men who have sex with men, ceftriaxone $250 \mathrm{mg}$ intramuscularly plus azithromycin $1 \mathrm{~g}$ orally is recommended for all forms of gonorrhea. ${ }^{3}$ tion. ${ }^{2}$ Populations at highest risk of gonococcal infection include people with multiple sexual partners, men who have sex with men and people who have a history of sexually transmitted infection, all factors in this patient.' The patient's ongoing urethritis may be related to persistent gonococcal infection or to co-infection with a second untreated genitourinary pathogen. Because of the high risk of co-infection with $C$. trachomatis in patients with documented gonorrhea, Canadian guidelines recommend empiric treatment for chlamydia, even if results of chlamydia testing (not done for this patient) are negative. ${ }^{3}$

\section{How should this patient's persistent urethral discharge be investigated?}

In men with symptomatic urethritis, Gram stain of a urethral specimen showing pus cells and intracellular gram-negative diplococci is more than $95 \%$ sensitive and more than $99 \%$ specific for the diagnosis of gonococcal urethritis. ${ }^{4}$ Although culture is a highly specific method for the diagnosis of gonorrhea (> 95\%), sensitivity is variable $(21 \%-$ $100 \%$ ) and is highly dependent on the adequacy of the specimen, transportation conditions and the experience of the testing microbiology laboratory. ${ }^{4}$ Nucleic acid amplification testing of both urine and urogenital specimens is highly sensitive for the diagnosis of both gonococcal and chlamydial urethritis. ${ }^{1}$ Both culture and nucleic acid amplification testing may be indicated in symptomatic men who have sex with men so that drug susceptibilities can be obtained to guide treatment. ${ }^{3}$ The preferred testing methods for gonorrhea according to anatomic site are presented in Table 1.,3

\section{If a diagnosis of persistent gonococcal urethritis is confirmed in this patient, how should it be treated?}

In the province of Ontario, Ota and colleagues ${ }^{5}$ described a rapid increase in the rate of fluoroquinolone-resistant $N$. gonorrhoeae from $4 \%$ of isolates in 2002 to $27.8 \%$ of isolates in 2006 . Fluoroquinolones, as prescribed to this patient, are no longer preferred agents for the treatment of gonococcal infection in Canada. Third-generation cephalosporins with adjuvant azithromycin are 
currently recommended as first-line treatment. ${ }^{3}$ However, decreasing susceptibility to cephalosporins among gonococcal isolates has recently been reported in the United States, East Asia and Europe, and is associated with treatment failure. ${ }^{6.7}$ This pattern of resistance is seen more commonly in men who have sex with men. ${ }^{6}$ A recent Canadian survey of $155 \mathrm{~N}$. gonorrhoeae isolates from 2001 to 2010 found an increase over time in the modal minimum inhibitory concentrations to both cefixime and ceftriaxone.

In 2011, in response to these changing patterns of resistance, the Public Health Agency of Canada revised its treatment guidelines for gonococcal infection (Table 1). ${ }^{3}$ Changes include the use of higher doses of cefixime ( $800 \mathrm{mg}$ as a single dose) or the use of intramuscular ceftriaxone $250 \mathrm{mg}$. A single intramuscular dose of ceftriaxone plus oral azithromycin is the preferred treatment of gonococcal infection in men who have sex with men, as well as for pharyngeal infection (Table 1). ${ }^{3}$ More recently, the US Centers for Disease Control and Prevention (CDC) recommended that oral cephalosporins no longer be used for the treatment of gonorrhea, based on recent data showing declining cefixime susceptibility among gonococcal isolates in the US. ${ }^{6}$ The CDC recommended that intramuscular ceftriaxone and oral azithromycin as a single dose or oral doxycycline for 7 days be used as dual therapy for gonorrhea. ${ }^{6}$

\section{If gonococcal infection is confirmed in this patient, is a posttreatment test of cure recommended?}

Follow-up cultures or a test of cure, done 1 week after treatment, is currently recommended in patients who are at high risk of relapse or reinfection. This includes patients with pharyngeal infection, patients with persistent symptoms after treatment, patients who received a treatment regimen not including a cephalosporin and patients with a partner who had a drug-resistant infection that was treated with that same antibiotic. ${ }^{3}$ Results of nucleic acid amplification testing may remain positive for up to 3 weeks after successful treatment, owing to the presence of residual DNA, ${ }^{1}$ which should be taken into consideration if culture is not available for test of cure. Patients experiencing a failure of treatment should be referred to a clinic specializing in the management of sexually transmitted infections.

\section{The case revisited}

Gram stain of the patient's urethral discharge showed pus cells and numerous intracellular gram-negative diplococci, compatible with $N$. gonorrhoeae infection (Figure 1). Results of urethral cultures were positive for $N$. gonor-

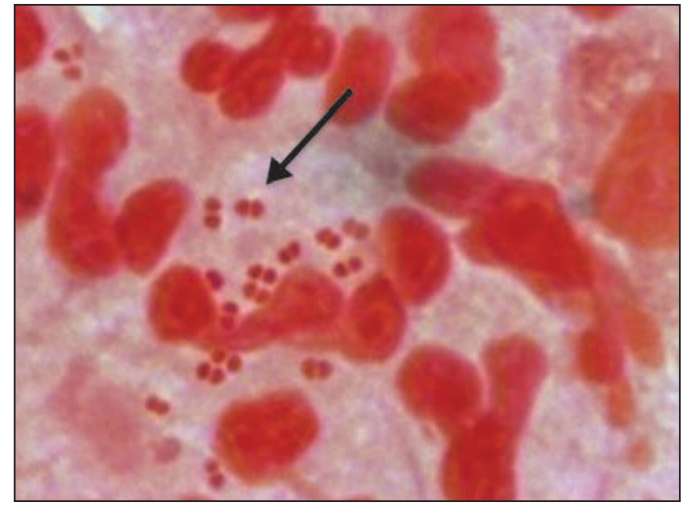

Figure 1: Gram stain of a urethral discharge showing polymorphonuclear cells and intracellular gram-negative diplococci (arrow) compatible with Neisseria gonorrhoeae infection (original magnification $\times 2000$ ).

rhoeae sensitive to ceftriaxone and cefixime and resistant to ciprofloxacin. Rectal and pharyngeal culture results were negative. Results of urine nucleic acid amplification testing for chlamydia were negative, as were tests for syphilis and antibodies to HIV types 1 and 2. Serology documented immunity to infection with hepatitis B virus. The patient was given ceftriaxone $250 \mathrm{mg}$ intramuscularly and azithromycin $1 \mathrm{~g}$ orally. Results of a urethral culture performed 1 week after treatment were negative. The patient's partner received a diagnosis of and treatment for asymptomatic gonococcal pharyngeal infection.

\section{References}

1. Public Health Agency of Canada. Canadian guidelines on sexually transmitted infections. Ottawa (ON): The Agency; 2006. Available: www.phac-aspc.gc.ca/std-mts/sti-its/guide-lignesdir -eng.php (accessed 2012 June 13).

2. Public Health Agency of Canada. Reported cases and rates of gonorrhea by province/territory and sex, 1980 to 2009. Ottawa (ON): The Agency; 2011. Available: www.phac-aspc.gc.ca/std-mts /sti-its_tab/gonorrhea_pts-eng.php (accessed 2012 June 29).

3. Public Health Agency of Canada. Important notice - public health information update on the treatment of gonoccocal infection. Ottawa (ON): The Agency; 2011. Available: www.phac-aspc .gc.ca/std-mts/sti-its/alert/2011/alert-gono-eng.php (accessed 2012 June 29).

4. Goodhart ME, Ogden J, Zaidi AA, et al. Factors affecting the performance of smear and culture tests for the detection of Neisseria gonorrhoeae. Sex Transm Dis 1982;9:63-9.

5. Ota KV, Jamieson F, Fisman DN, et al. Prevalence of and risk factors for quinolone-resistant Neisseria gonorrhoeae infection in Ontario. CMAJ 2009; 180:287-90.

6. Update to CDC's sexually transmitted diseases treatment guidelines. 2010: oral cephalosporins no longer a recommended treatment for gonococcal infections. MMWR Morb Mortal Wkly Rep 2012;61:590-4

7. Martin I, Sawatzky P, Allen V, et al. Emergence and characterization of Neisseria gonorrhoeae isolates with decreased susceptibilities to ceftriaxone and cefixime in Canada: 2001-2010. Sex Transm Dis 2012;99:316-23.

Affiliations: From the Department of Medicine (Rebick, Allen, Gold), University of Toronto; Public Health Ontario (Allen); the Division of Infectious Diseases (Allen), Sunnybrook Health Sciences Centre; and the Division of Infectious Diseases (Gold), University Health Network, Toronto, Ont.

Contributors: All of the authors drafted and revised the article and approved the final version submitted for publication. 